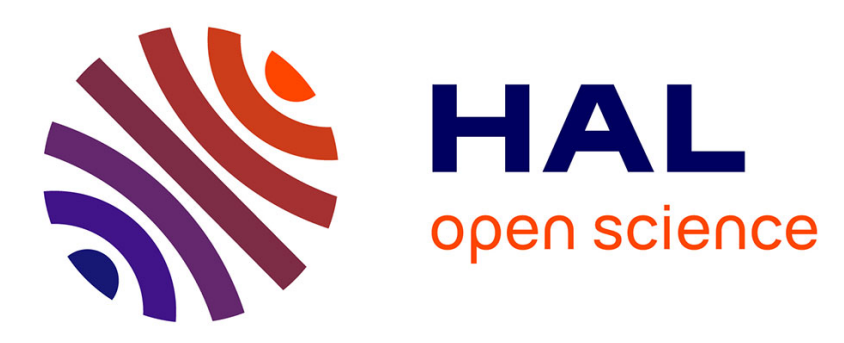

\title{
Self-crosslinking smart hydrogels through direct complexation between benzoxaborole derivatives and diols from hyaluronic acid
}

\author{
Tamiris Figueiredo, Yu Ogawa, Jing Jing, Vanina Cosenza, Isabelle \\ Jeacomine, Johan D M Olsson, Thibaud Gerfaud, Jean-Guy Boiteau, Craig \\ Harris, Rachel Auzely-Velty
}

\section{To cite this version:}

Tamiris Figueiredo, Yu Ogawa, Jing Jing, Vanina Cosenza, Isabelle Jeacomine, et al.. Self-crosslinking smart hydrogels through direct complexation between benzoxaborole derivatives and diols from hyaluronic acid. Polymer Chemistry, 2020, 11, pp.3800-3811. 10.1039/D0PY00308E . hal-03005698

\section{HAL Id: hal-03005698 \\ https://hal.science/hal-03005698}

Submitted on 30 Nov 2020

HAL is a multi-disciplinary open access archive for the deposit and dissemination of scientific research documents, whether they are published or not. The documents may come from teaching and research institutions in France or abroad, or from public or private research centers.
L'archive ouverte pluridisciplinaire HAL, est destinée au dépôt et à la diffusion de documents scientifiques de niveau recherche, publiés ou non, émanant des établissements d'enseignement et de recherche français ou étrangers, des laboratoires publics ou privés. 


\section{Self-crosslinking smart hydrogels through direct complexation be- tween benzoxaborole derivatives and diols from hyaluronic acid}

Received 00th January 20xx, Accepted 00th January 20xx

DOI: $10.1039 / \times 0 x x 00000 x$
Tamiris Figueiredo, ${ }^{a}$ Yu Ogawa, ${ }^{a}$ Jing Jing, ${ }^{b}$ Vanina Cosenza, ${ }^{a}$ Isabelle Jeacomine, ${ }^{a}$ Johan D. M. Olsson, ${ }^{c}$ Thibaud Gerfaud, ${ }^{b}$ Jean-Guy Boiteau, ${ }^{b}$ Craig Harris, ${ }^{b}$ Rachel Auzély-Velty*a
Boronate ester cross-linked hydrogels have emerged as promising injectable scaffolds for biomedical applications given their rapid self-healing ability. For a rational design of such networks, all variables influencing their dynamic rheological properties, especially the boronic acid and the diol-containing molecule selected as molecular crosslinkers have to be carefully considered. Herein, by tailoring the structure of benzoxaborole (BOR), self-crosslinking hydrogels based on hyaluronic acid (HA) modified with BOR derivatives are obtained for the first time through the direct BOR-HA diol complexation at physiological pH. Among the different HA-BOR conjugates investigated, those prepared from 6-amino-7fluoro-3,3-dimethyl benzoxaborole (HA-DMF6ABOR) and 7-amino-3,3-dimethyl benzoxaborole (HA-DM7ABOR) show unprecedented self-crosslinking properties, leading to the formation of self-healing hydrogels with extremely slow dynamics. These networks also exhibit remarkable $\mathrm{pH}$ - and glucose-responsive behaviors. These properties are related to the peculiar structure of these two BOR moieties, having as the common feature, a gem-dimethyl group in the oxaborole ring and an ortho-substituent in the phenyl ring. Molecular dynamic simulations are used to provide insight in the role of these substituents in the outstanding capability of DMF6ABOR and DM7ABOR to crosslink HA. They show that BOR complexation induces changes in conformation of $\mathrm{HA}$ favoring formation of a highly entangled 3D network

\section{Introduction}

Boronic acid-containing macromolecules have gained increasing attention in recent years due to their potential as recognition element in carbohydrate-responsive platforms and sensors, and as building block for the construction of dynamic polymeric assemblies. $^{1,2}$ Among polymeric assemblies, hydrogels crosslinked through boronate-diol complexes have emerged as promising injectable materials for drug delivery and tissue engineering mainly because of their self-healing ability. ${ }^{3-7}$ This property is related to the dynamic covalent nature of these bonds allowing hydrogels to reconfigure their covalent structure, and thereby to self-repair without any external stimuli after rupture. ${ }^{8-10}$ In these hydrogels, the formation of boronate ester crosslinks depends on the binding affinity $\left(K_{a}\right)$ of the boronic acid derivative for a given diol or polyol, which is influenced by the $\mathrm{pH}$ of the medium, and the $\mathrm{p} K_{a}$ of the small molecular partners. ${ }^{11,12}$ Boronate ester formation is indeed expected to be favored at a $\mathrm{pH}$ value half-way between the $\mathrm{p} K_{a}$ of the phenylboronic acid and the $\mathrm{p} K_{a}$ of the diol. ${ }^{13}$ As most of arylboronic acids used to fabricate hydrogels have a $\mathrm{p} K_{a}$ in the range of $8-9$, such as phenylboronic acid (PBA, $\mathrm{p} K_{a} \quad 8.8^{14}$ ), $\mathrm{pH}$ values above physiological $\mathrm{pH}$ are often required to trigger gel formation by shifting the equilibrium towards the boronate ester. One method of synthetic manipulation used to improve formation of boronate crosslinks at neutral $\mathrm{pH}$ is to modify the PBA moiety by adding electron-withdrawing groups on the phenyl ring (i.e. fluorine, nitro) that reduce its $\mathrm{p} K_{a} \cdot{ }^{15-18}$ Such an approach was successfully

\footnotetext{
a. Univ. Grenoble Alpes, Centre de Recherches sur les Macromolécules Végétales (CERMAV)-CNRS, 601, rue de la Chimie, BP 53, 38041 Grenoble Cedex 9 (France).

b. Galderma/Nestlé Skin Health R\&D, 2400 Route de Colles, 06410 Biot (France).

c. Galderma/Nestlé Skin Health R\&D, Seminariegatan 21, SE-752 28 Uppsala (Sweden).

Electronic Supplementary Information (ESI) available: [details of any supplementary information available should be included here]. See DOI: $10.1039 / x 0 x \times 00000 x$
}

applied by Yesilyurt et al. to enhance the dynamic mechanical properties of poly(ethylene glycol) (PEG)-based self-healing networks at physiological $\mathrm{pH}^{3}{ }^{3}$ Indeed, using a four-arm PEG derivative modified with 4-carboxy-3-fluorophenylboronic acid $\left(p K_{a}\right.$ 7.2) instead of 4-carboxyphenylboronic acid $\left(p K_{a} 7.8\right)$ for network formation with a four-arm PEG derivative containing glucose-like moieties, the authors obtained assemblies with increased dynamic moduli and a lower relaxation time.

Besides, the position of the substituents on the aromatic ring was also demonstrated to have strong effect on boronic acid/diol complexation. In the case of 2-acrylamidophenylboronic acid (2APBA), the participation of the amido group at the ortho-position relative to the boronic acid through an intramolecular B-Ocoordinated interaction was thus found to induce boron changes from the trigonal planar form to the anionic tetrahedral form, favoring binding with glucose. ${ }^{19}$ By using this 2-APBA monomer to prepare boronic acid-containing copolymers, Deng et al. showed the ability to obtain hydrogels at neutral and acidic $\mathrm{pH}$ via boronate ester formation with diol-containing polymers. ${ }^{20}$

As one of the ortho-substituted arylboronic acids, ohydroxymethylphenylboronic acid (benzoxaborole, BOR) stands out not only for its efficient carbohydrate-binding capability at physiological $\mathrm{pH}$ but also for its ability to complex sugars locked in their pyranose form (i.e. glycopyranosides). ${ }^{21-23}$ Compared to PBA, BOR has a lower $\mathrm{p} K_{a}$ (7.3) due to its strained 5-membered oxaborole ring, ${ }^{24,25}$ which is a contributing factor explaining its exceptional carbohydrate-binding behavior. This property was successfully used to prepare self-healing hydrogel networks at physiological $\mathrm{pH}$ by combining synthetic copolymers containing benzoxaborole moieties and various saccharide derivatives (glucose, lactose and mannose derivatives). ${ }^{4,5,26-28}$ Recently, we also demonstrated ability to form self-healing hydrogels by mixing hyaluronic acid (HA) modified with benzoxaborole and HA functionalized with a D-fructose derivative. ${ }^{29}$ Nevertheless, despite the capability of BOR to bind glycopyranosides, to date, 
there have been no published studies investigating formation of reversible hydrogels from benzoxaborole-modified polysaccharides via direct complexation between BOR and saccharide units in the biopolymer chain. While offering economy of raw materials and a simpler methodology for gel synthesis, such an approach may also benefit from the unique properties of natural polysaccharides such as biocompatibility and biodegradability. It should be noted that recently, a selfcrosslinking polysaccharide gel was obtained under basic aqueous conditions from alginate functionalized with 3aminophenylboronic acid moieties that can reversibly bind the vicinal diols of the alginate pyranose rings. ${ }^{30}$ However, the synthesis of self-crosslinking hydrogels from one single polysaccharide component has never been demonstrated at neutral $\mathrm{pH}$.

The present work establishes for the first time the feasibility of self-crosslinking hyaluronic acid hydrogel formation at physiological $\mathrm{pH}$ by taking advantage of the glycopyranosidebinding capability of benzoxaborole. Inspired by previous studies showing significant effects of substituents introduced on PBA as well as of their position on its diol-binding capability at neutral $\mathrm{pH}$, we tailored the structure of BOR to promote binding to $\mathrm{HA}$ saccharides. To this end, several aminobenzoxaborole derivatives were synthesized with variations in both the position of the amine group on the phenyl ring and the structure of the oxaborole ring (Figure 1a). These consist of 4-, 5-, 6- and 7aminobenzoxaborole and their counterpart (i.e. 4-, 5-, 6- and 7amino-3,3-gem-dimethylbenzoxaborole) in which the 5membered heterocycle is substituted at the 3 position by bulky methyl groups. Moreover, besides these eight derivatives, two additional BOR derivatives (6-aminobenzoxaborole and 6-amino3,3-gem-dimethylbenzoxaborole) with a fluorine substituent in the ortho-position to the boron were also investigated to address the question of the role of the phenyl ring substitution by an electron-withdrawing group in the binding of BOR to HA. Of note, despite many studies on the structure-property relationships of

a)

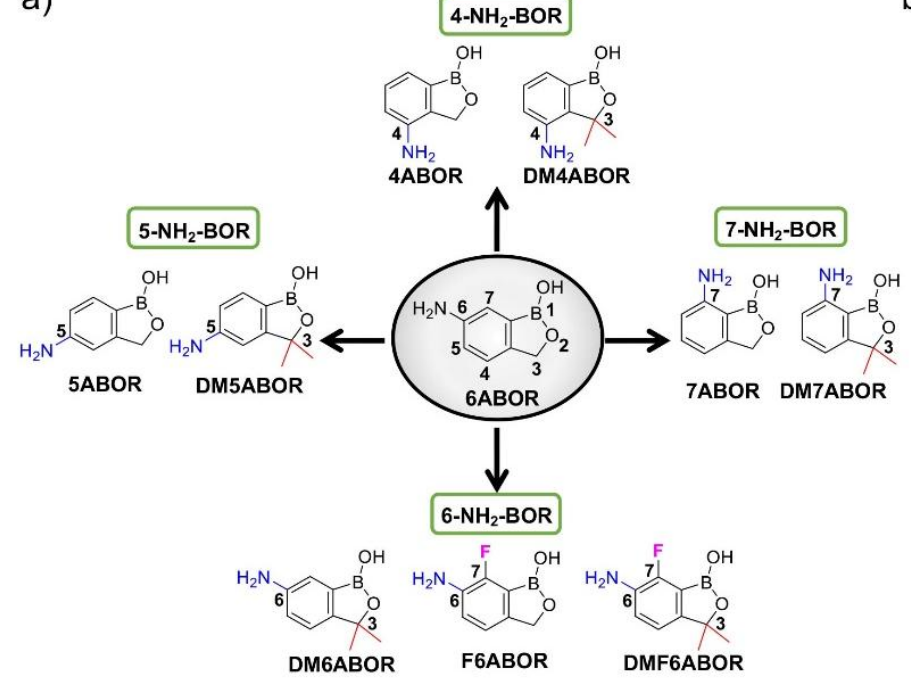

the BOR molecule related to its great potential for drug development and saccharide sensing, ${ }^{24,25}$ the effect of structural BOR modification on the bulk mechanical properties of hydrogels has not previously been investigated.

Very interestingly, among all the HA-BOR conjugates studied, those prepared from 7-amino-3,3-gem-dimethylbenzoxaborole (DM7ABOR) and fluoro-substituted 6-amino-3,3-gemdimethylbenzoxaborole (DMF6ABOR) showed unprecedented self-crosslinking properties, leading to the formation of selfhealing hydrogels with extremely slow dynamics (Figure 1b). Following the identification of this special class of HA derivatives, we further investigated the mechanism of reversible covalent complexation of the grafted BOR moieties with HA in more details by combining dynamic rheological measurements in various environmental conditions and molecular dynamics studies. These revealed original properties for the HA-DM7ABOR and HA-DMF6ABOR hydrogels, ranging from self-healing capability to stimuli-responsive behaviors triggered by $\mathrm{pH}$ and addition of glucose. These unique features open the door to many innovative applications in the biomedical field.

\section{Materials and methods}

Materials. Sodium hyaluronate samples possessing a weight average molar mass $\left(\mathrm{M}_{\mathrm{w}}\right)$ of 100 and $360 \mathrm{~kg} / \mathrm{mol}$ were supplied by Lifecore Biomedical (USA) and donated by Galderma-Nestlé Skin Health, respectively. The molar mass distribution and the weight-average molar mass of these samples were determined by size exclusion chromatography using a Waters GPC Alliance chromatograph (USA) equipped with a differential refractometer and a light scattering detector (MALLS) from Wyatt (USA); the solutions were injected at a concentration of $1 \times 10^{-3} \mathrm{~g} / \mathrm{mL}$ in 0.1 $\mathrm{M} \mathrm{NaNO}_{3}$, at a flow rate of $0.5 \mathrm{~mL} \mathrm{~min}$ and at a column temperature of $30{ }^{\circ} \mathrm{C}$. The polydispersity of the samples is $\theta \approx$ $1.5-$

b)
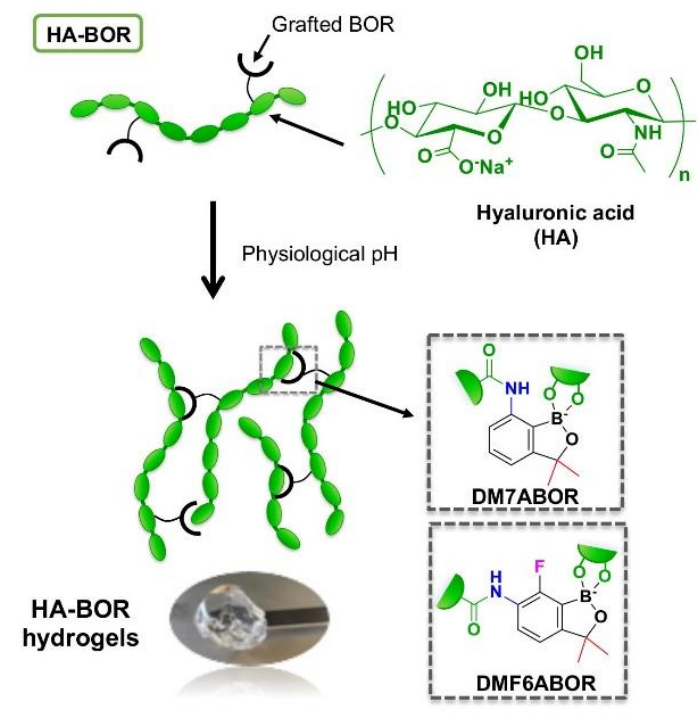
Figure 1. (a) Tailor-made aminobenzoxaborole (ABOR) derivatives synthesized with variations in both the position of the amine group on the phenyl ring and the structure of the oxaborole ring. (b) Self-healing HA hydrogels obtained from single BOR-modified HA conjugates able to self-assemble at physiological $\mathrm{pH}$ via dynamic benzoxaborole-HA linkages. 
2. The overlap concentration $C^{*}$ for the HA100 and HA360 samples in phosphate buffer saline $\left(\mathrm{pH} \mathrm{7.4)}\right.$ at $25^{\circ} \mathrm{C}$ is around 3 and $1 \mathrm{~g} / \mathrm{L}$, respectively. These values were derived from the intrinsic viscosity assuming that $C^{*}[\eta]$ is about unity. ${ }^{31}$ 5-Amino2-hydroxymethylphenylboronic acid (6-aminobenzoxaborole, 6ABOR) was purchased from Combi-Blocks. 4-(4,6-dimethoxy1,3,5-triazin-2-yl)-4-methylmorpholinium chloride (DMTMM), 4(2-hydroxyethyl)piperazine-1-ethanesulfonic acid (HEPES), phosphate buffered saline (PBS) and other chemicals were purchased from Sigma-Aldrich and were used without further purification. The syntheses of the different aminobenzoxaborole derivatives are described in the Supporting Information.

Synthesis of the HA-benzoboxorole conjugates. All HA-BOR conjugates were synthesized by an amide coupling reaction in hydro-organic conditions. This consisted in adding DMTMM (0.207 g, $0.75 \mathrm{mmol})$ in a water/DMF $(3 / 2, \mathrm{v} / \mathrm{v})$ solution containing $\mathrm{HA}(0.3 \mathrm{~g}, 0.75 \mathrm{mmol}$ ) at a concentration of $3 \mathrm{~g} / \mathrm{L}$ (for $\mathrm{HA}$ with $\mathrm{M}_{\mathrm{w}}=100 \mathrm{~kg} / \mathrm{mol}$ ) and $2 \mathrm{~g} / \mathrm{L}$ (for $\mathrm{HA}$ with $\mathrm{M}_{\mathrm{w}}=360$ $\mathrm{kg} / \mathrm{mol}$ ). The reaction mixture was kept under stirring at room temperature for $15 \mathrm{~min}$ followed by addition of each aminobenzoxaborole compound (BOR) at an amine/HA molar ratio of 0.15 . The $\mathrm{pH}$ of the medium was adjusted to 6.5 using 0.5 $\mathrm{M} \mathrm{NaOH}$ and the reaction mixture was kept under stirring at room temperature for 24-46 h, depending on the BOR derivative. The final product was then purified by ultrafiltration against water and recovered by freeze-drying in 95-98\% yields. All HABOR conjugates were synthesized with a DS of $0.1-0.15$, as determined by ${ }^{1} \mathrm{H}$ NMR spectroscopy (Figure S1-S11, SI, and Figure 2).

NMR spectroscopy. ${ }^{1} \mathrm{H},{ }^{13} \mathrm{C}$ and ${ }^{11} \mathrm{~B}$ NMR spectra were recorded at $25{ }^{\circ} \mathrm{C}$ or $80{ }^{\circ} \mathrm{C}$ using a Bruker AVANCE III HD spectrometer operating at $400.13 \mathrm{MHz}\left({ }^{1} \mathrm{H}\right), 100.61 \mathrm{MHz}\left({ }^{13} \mathrm{C}\right)$ and $128.38 \mathrm{MHz}$ $\left({ }^{11} \mathrm{~B}\right) .{ }^{1} \mathrm{H}$ NMR spectra were recorded by applying a $90^{\circ}$ tip angle for the excitation pulse, and a $10 \mathrm{~s}$ recycle delay for accurate integration of the proton signals. ${ }^{13} \mathrm{C}$ NMR spectra were recorded by applying a $90^{\circ}$ tip angle for the excitation pulse and a $2 \mathrm{~s}$ recycle delay. Deuterium oxide $\left(D_{2} O\right)$ was obtained from Eurisotop (Saint-Aubin, France). Chemical shifts ( $\delta$ in ppm) are given relative to external tetramethylsilane (TMS $=0 \mathrm{ppm})$ and calibration was performed using the signal of the residual protons of the solvent as a secondary reference. All NMR spectra were analyzed with Topspin 3.1 software from Bruker AXS.

Determination of the $\mathrm{PK}_{\mathrm{a}}$ of DMF6ABOR, DM7ABOR and 6ABOR by ${ }^{11} B$ NMR spectroscopy. ${ }^{11} B$ NMR chemical shifts of the aminobenzoxaborole compounds were determined with increasing $\mathrm{pH}\left(10 \% \mathrm{D}_{2} \mathrm{O}\right.$ in $\mathrm{H}_{2} \mathrm{O}, 16 \mathrm{mM}$ in $0.01 \mathrm{M}$ phosphate buffer). Chemical shifts ( $\delta$ in ppm) for each ${ }^{11} \mathrm{~B}$ spectrum were given relative to external $\mathrm{Et}_{2} \mathrm{O}-\mathrm{BF}_{3}$ in deuterated chloroform as zero. The values of $\mathrm{pK}_{\mathrm{a}}$ were determined from the curve fitting of the variation of $\delta$ (in $\mathrm{ppm}$ ) with the $\mathrm{pH}$ using the Boltzmann equation (Figure $\mathrm{S} 12, \mathrm{SI}$ ).

Determination of the binding constants by ITC. Calorimetric titration experiments were carried out on a Microcal VP-ITC titration microcalorimeter (Northampton, U.S.A.). All titrations were made using solutions of free DMF6ABOR or DM7ABOR (free BOR- $\mathrm{NH}_{2}$ compounds) and free D-fructose first prepared by solubilization in deionized water, with $\mathrm{pH}$ adjusted to $7.4( \pm 0.1)$ using a $\mathrm{pH}$-meter by carefully adding $1 \mathrm{M} \mathrm{NaOH}$ when necessary. Then, the solutions were diluted with $0.02 \mathrm{M} \mathrm{PBS} \mathrm{pH} 7.4$ in order to obtain final solutions in $0.01 \mathrm{M} \mathrm{PBS}$ at $\mathrm{pH}$ 7.4. The reaction cell $(\mathrm{V}=1.4478 \mathrm{~mL}$ ) contained a solution of a BOR derivative (Table 1). A series of 28 injections of 5 or $10 \mu \mathrm{L}$ of a solution of $\mathrm{D}$ fructose was made from a computer-controlled $300 \mu \mathrm{L}$ microsyringe at an interval of $400 \mathrm{~s}$ into the solution contained in the reaction cell, while stirring at $300 \mathrm{rpm}$ at $25^{\circ} \mathrm{C}$. The raw experimental data were reported as the amount of heat produced after each injection of BOR derivative as a function of time. The amount of heat produced per injection was calculated by integration of the area under individual peaks by the instrument software, after taking into account heat of dilution. The data were analyzed utilizing the one set of site fitting model (Origin 7.0 software package). Table 1 summarizes the experimental conditions used.

Table 1. Experimental conditions of the calorimetric titrations.

\begin{tabular}{ccccc}
\hline Entry & $\begin{array}{c}\text { D-fructose in } \\
\text { syringe }\end{array}$ & $\begin{array}{c}\text { [D-fructose }] \\
(\mathrm{mM})\end{array}$ & $\begin{array}{c}\text { Free BOR-NH} \mathrm{N}_{2} \text { in } \\
\text { cell }\end{array}$ & $\begin{array}{c}{\left[\mathrm{BOR}-\mathrm{NH}_{2}\right]} \\
(\mathrm{mM})\end{array}$ \\
\hline 1 & D-fructose & 75 & $6 \mathrm{ABOR}$ & 2 \\
2 & D-fructose & 37.5 & DMF6ABOR & 1 \\
3 & D-fructose & 56 & DM7ABOR & 1.5
\end{tabular}

Preparation of the hydrogel formulations based on HA-BOR conjugates. Formulations of HA-BOR derivatives were prepared by simply solubilizing their lyophilized powder recovered from their syntheses in $0.01 \mathrm{M}$ HEPES buffer ( $\mathrm{pH}$ 7.4) containing 0.15 $\mathrm{M} \mathrm{NaCl}$. Salt was added in order to screen the long range electrostatic repulsions between negatively charged chains. The dissolution time was at least $12 \mathrm{~h}$ at $4{ }^{\circ} \mathrm{C}$ under stirring. All formulations were prepared at a total polymer concentration of $15 \mathrm{~g} / \mathrm{L}$. To study the rheological properties of HA hydrogels as a function of $\mathrm{pH}, 0.01 \mathrm{M}$ HEPES buffers containing $0.15 \mathrm{M} \mathrm{NaCl}$ with $\mathrm{pH}$ values adjusted to 4, 6, 6.5 and 7 were prepared. Competition studies were performed by preparing HA hydrogels

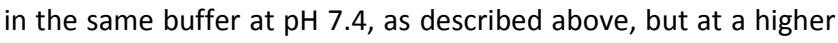
concentration of HA. Then, diol-containing molecules solubilized in the same buffer were added in the gel formulations at room temperature under vortex stirring, in order to obtain a total polymer concentration of $15 \mathrm{~g} / \mathrm{L}$. All mixtures were kept under stirring at $4{ }^{\circ} \mathrm{C}$ overnight before rheological analysis.

Rheological experiments. Oscillatory experiments were performed with a cone-plate rheometer (AR2000EX from TA Instruments). All the dynamic rheological data were checked as a function of strain amplitude to ensure that the measurements were performed in the linear viscoelastic region. No frequency data beyond $10 \mathrm{~Hz}$ are presented because inertial artefacts (raw phase angle $>150^{\circ}$ ) were observed at frequencies higher than 10 $\mathrm{Hz}^{32,33}$ The cone used for viscoelastic samples has a diameter of $2 \mathrm{~cm}$ and an angle of $4^{\circ}$, whereas viscous solutions were analyzed using a cone of $6 \mathrm{~cm}$ of diameter and an angle of $1^{\circ}$. To prevent water evaporation, the measuring system was surrounded with a low-viscosity silicone oil (50 $\mathrm{mPa}$ s) carefully added to the edges of the cone.

Computational methods. First, two possible complexes of DMF6ABOR with HA saccharides (using a HA with 2 repeating 
disaccharide units) were studied, with the BOR derivative bound to (i) the C-4/C- 6 diol of the D-GIcNAc unit or (ii) the C-2/C-3 diol pair of the D-Glc unit (Figure S13, SI). For a better representation of the DMF6ABOR derivative which is grafted to $H A$, a DMF6ABOR model containing a tert-butyl group coupled to its amide moiety was used to simulate the steric effect of the HA chain. Force field molecular dynamics (MD) simulations were carried out on the complexes. The MD simulations were performed in the GROMACS software, ver. $2018^{34}$ with all-atom Gromos $54 a 7$ force field. ${ }^{35}$ All the production MD simulations were performed in an NPT (constant number of atoms, pressure, and temperature) ensemble with velocity-rescale temperature coupling $^{36}$ and Berendsen pressure coupling algorithms ${ }^{37}$ with temperature and pressure coupling constants of 0.2 ps and 2 ps, respectively. Each complex was placed in a box with dimensions with approximately $8 \times 8 \times 8 \mathrm{~nm}^{3}$ where single point charge (SPC) water molecules ${ }^{38}$ were filled. The structure was then relaxed with energy minimization followed by MD simulation with slow heating from $0 \mathrm{~K}$ to $300 \mathrm{~K}$ in $2 \mathrm{~ns}$. The system was then equilibrated for $10 \mathrm{~ns}$ at $300 \mathrm{~K}$. The production run was performed for $20 \mathrm{~ns}$ at $300 \mathrm{~K}$. Further simulations were performed under the same simulation parameters with systems composed of two HA chains, each made of 6 repeating disaccharide units, possessing a single BOR-modified crosslinker covalently bound to both HA chains approximately at the middle of each chain. Three systems were constructed with DM6ABOR, DMF6ABOR, and DM7ABOR, respectively. They were placed in a box filled with SPC water molecules and energy minimized. The systems were equilibrated for $10-20 \mathrm{~ns}$ at $300 \mathrm{~K}$, followed by the production simulation for 10 to $50 \mathrm{~ns}$ at the same temperature. The end to end vector of each $\mathrm{HA}$ chain was defined between $\mathrm{C} 4$ atom at the non-reducing end and $\mathrm{C} 1$ atom at the reducing end.

\section{Results}

Synthesis of benzoxaborole-modified HA and behavior in aqueous solution at neutral $\mathrm{pH}$. The synthesis of the different benzoxaborole-modified HA required first that of aminobenzoxaborole derivatives. These custom-made products, except 6-aminobenzoxaborole (6ABOR) which is commercially available, were synthesized in four to seven steps, as described in the Supporting Information, and were isolated with yields comprised between 41-86 \%. To properly investigate the selfcrosslinking properties of the different HA-BOR conjugates, all HA derivatives were synthesized from the same HA sample, possessing a weight average molar mass $\left(M_{w}\right)$ of $100 \mathrm{~kg} / \mathrm{mol}$ (referred to as HA100), and with a similar degree of substitution (DS, average number of substituting group per repeating disaccharide unit). The HA-BOR conjugates were prepared by an amide coupling reaction in aqueous solution between BOR derivatives containing a primary amine group in position $4,5,6$ or 7 on the aromatic ring and HA, using 4-(4,6-dimethoxy-1,3,5triazin-2-yl)-4-methylmorpholinium chloride (DMTMM) as a coupling agent (Figure 2). ${ }^{39}$ The DS of the HA conjugates was controlled by the amount of BOR derivative and DMTMM. Herein, we used BOR derivative/HA and DMTMM/HA molar ratios of 0.15 and 1 , respectively, to obtain DS values in the range of 0.1-0.15. The resulting HA conjugates were isolated in 95-98 \% yields after purification by a diafiltration process using deionized water and freeze-drying. Successful grafting of BOR moieties on HA was confirmed by ${ }^{1} \mathrm{H}$ NMR spectroscopy, which also allowed determination of the DS (Figure 2, Figure S1-S9, SI).

Figure 2 shows that the reactivity of the BOR compounds depends on the position of the amine group on the aromatic ring as well as on the fluorine substitution. The 6ABOR and DM6ABOR derivatives with the amine group in meta-position were thus found to be more reactive towards the carboxyl group of HA compared to the other ones, including the fluoro-substituted derivatives F6ABOR and DMF6ABOR. Of note, no grafting on HA was observed when using DM4ABOR (Figure 2), which can be ascribed to steric hindrance of the methyl substituents adjacent to the amine group.

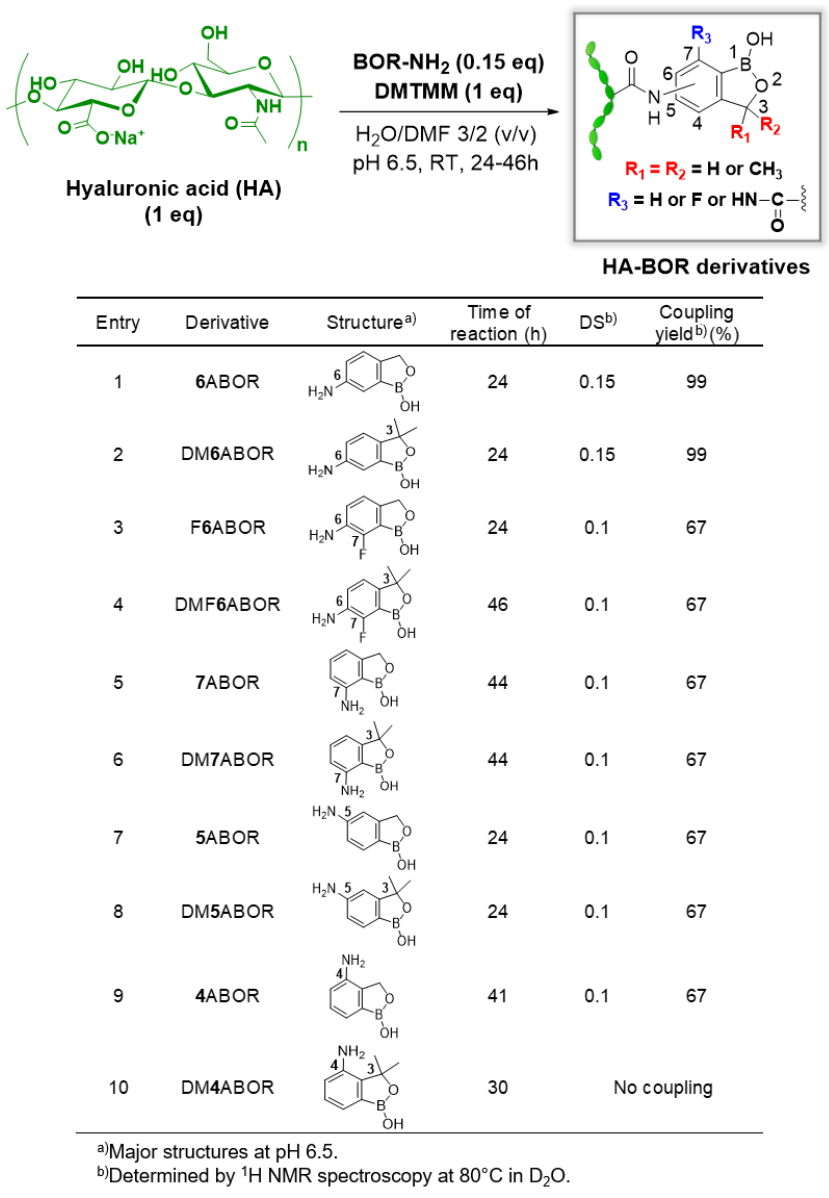

Figure 2. Reaction scheme and conditions for the synthesis of the different HA-BOR derivatives by amide bond formation in aqueous conditions using initial $\mathrm{HA}$ with $\mathrm{Mw}=100 \mathrm{~kg} / \mathrm{mol}$.

To test gel formation via complexation of BOR moieties with HA saccharide units, all HA-BOR conjugates were simply solubilized in aqueous solution at physiological pH (0.01 M HEPES, $0.15 \mathrm{M}$ $\mathrm{NaCl})$, at a total polymer concentration $\left(C_{p}=15 \mathrm{~g} / \mathrm{L}\right)$ higher than the overlap concentration of initial $\mathrm{HA}\left(C^{*} \approx 3 \mathrm{~g} / \mathrm{L}\right)$. After stirring overnight at $4{ }^{\circ} \mathrm{C}$, visual observations by inverting the vials of the different samples suggested formation of transparent hydrogels for HA-DMF6ABOR and HA-DM7ABOR. Dynamic rheological analyses confirmed the gel-like behavior $\left(G^{\prime}>G^{\prime \prime}\right.$ in the 
frequency window explored) for these two derivatives (Figure 3a and $3 b$ ). Furthermore, with the exception of HA-6ABOR, giving rise to a viscous solution like initial $H A$, all the other $H A$ derivatives exhibited a viscoelastic behavior (crossover of $\mathrm{G}^{\prime}$ and $G^{\prime \prime}$ seen within the tested frequencies, Figure $3 a, b$ and $c$ ). These results thus revealed formation of new interactions between $H A$ chains that strongly depends on the structure of the BOR derivatives grafted on $H A$. Some of the striking examples include the $6 A B O R$ and the 7ABOR derivatives linked to HA, which confer to the polysaccharide very different dynamic rheological properties upon introduction of a gem-dimethyl group in the oxaborole ring and/or a fluorine atom in the phenyl ring. The fact that slight modifications in the BOR molecule induce dramatical changes in the macroscopic mechanical behavior led us to rule out the idea that interactions between HA chains are mediated by hydrophobic interactions between BOR moieties. Furthermore, ${ }^{1} \mathrm{H}$ NMR spectra of the HA-BOR derivatives provided some evidence of selective interaction between the grafted BOR moieties and HA saccharides. In the spectra of most HA-BOR derivatives (Figure S3-S7, SI), the proton signals in the aromatic region exhibited splitting, suggesting the presence of free and complexed BOR species which are in slow exchange on the NMR timescale. It can be noted that similar observations were previously made for complexation of commercial free 6ABOR with D-fructose, for which benzoxaborole has the highest affinity compared to D-glucose and hexopyranosides at neutral $\mathrm{pH}^{21,22}$

Interestingly, the comparison of the variation of the loss factor, $\tan \delta$ (defined as $G^{\prime \prime} / G^{\prime}$ ), with frequency for the different HA derivatives revealed a common feature in the HA modified with
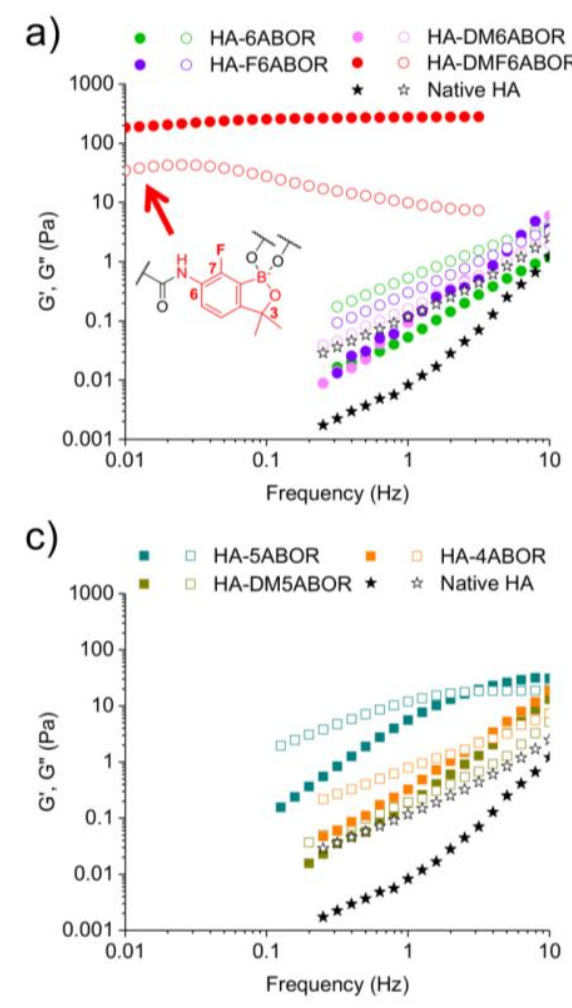

d)

5-, 6- and 7ABOR (Figure 3d). Whatever the family, the HADMABOR derivative shows systematically lower loss factor values than its HA-ABOR counterpart. This trend correlates with the lower crossover frequency where $G^{\prime}=G^{\prime \prime}$ (i.e. $\omega_{c}$ which can be considered as the inverse of the characteristic relaxation time of the network), for HA-DMABOR in comparison to its HA-ABOR counterpart (Figure $3 a, b$ and $c$ ). These data thus indicate that the gem-dimethyl group in the oxaborole ring plays a key role in the binding to $\mathrm{HA}$, resulting macroscopically in a decrease of the network dynamics and in most cases, an increase of the $G^{\prime}$ and G' moduli. In this regard, an increase of $\mathrm{p} K_{a}$ to 8.3 was reported for 3,3-gem-dimethyl benzoxaborole (DMBOR) in comparison to BOR $\left(\mathrm{p} K_{a}=7.3\right) .{ }^{40}$ This was attributed to steric bulk caused by the gem-dimethyl group at the 3-position in the oxaborole ring, which likely increases the bond angle around boron, alleviating the bond distortion and disfavoring ionization. The results obtained in the present work, indicating that the DMABOR moieties are more tightly bound to HA than their ABOR counterparts, are not consistent with the general belief that boronic acids with lower $\mathrm{p} K_{a}$ values show greater binding affinities for diols, as had already been pointed out previously. ${ }^{13}$ It is also worth noting from Figure $3 \mathrm{~d}$ that HA-DMF6ABOR and HA-DM7ABOR stands out by displaying loss factor values lower than 1 , indicating that the samples behave more like a soft elastic solid. On the basis of these results, these two derivatives were selected for more extensive physico-chemical studies with respect to their potential applications as injectable biomaterials.

Effect of molar mass and environmental parameters on the dynamic mechanical properties of HA-DMF6ABOR and HADM7ABOR conjugates. Assuming that tailoring the molar mass of
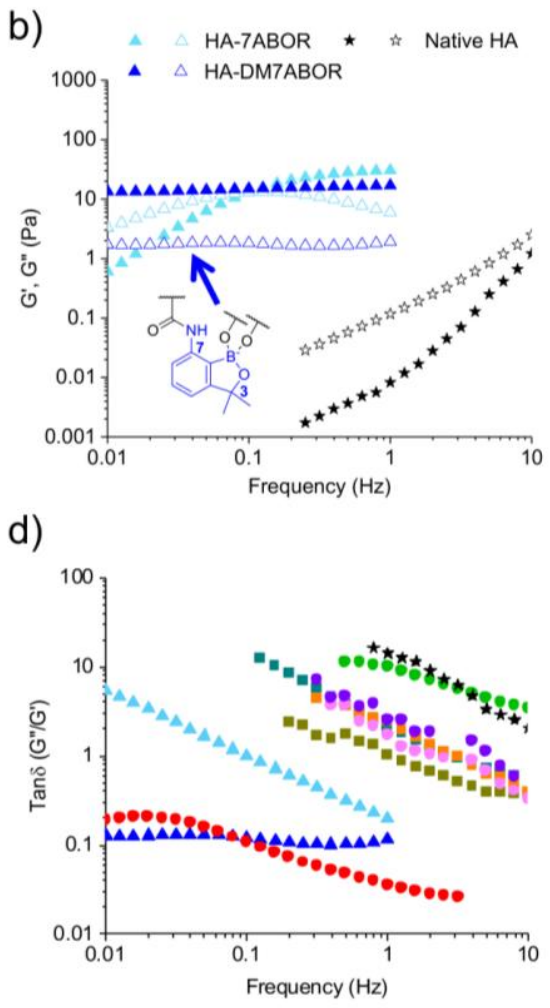

Figure 3. Dynamic rheological behavior of the HA-BOR conjugates prepared from HA100. Frequency dependence of the storage modulus $\left(G^{\prime}\right.$, filled symbols) and loss modulus ( $G^{\prime \prime}$, empty symbols) for the formulations based on HA modified with 6-amino-BOR derivatives (a), 
7-amino-BOR derivatives (b) and 5- (or 4)-amino-BOR derivatives (c). (d) Frequency dependence of tan( $\delta$ ) for all HA formulations; samples are referred to the same symbols as used in Figure a-c.

HA can modulate the degree of interactions between HA chains via BOR complexation, we prepared new HA-DMF6ABOR and HADM7ABOR conjugates using an initial HA sample possessing a weight-average molar mass $\left(M_{w}\right)$ of $360 \mathrm{~kg} / \mathrm{mol}$ (referred to as HA360), while keeping the same DS (i.e. 0.1, see Table S1 and Figure S10 and S11, SI). Figure 4 compares the rheological properties of aqueous formulations at physiological $\mathrm{pH}$ of $\mathrm{HA}$ DMF6ABOR and HA-DM7ABOR prepared from HA100 and HA360. As expected, the two higher $M_{w}$ HA derivatives (HA360DMF6ABOR and HA360-DM7ABOR) exhibited a hydrogel behavior with higher values of $G^{\prime}$ in the plateau region (371 \pm 44 $\mathrm{Pa}$ and $160 \pm 57 \mathrm{~Pa}$, respectively) than HA100-DMF6ABOR and HA100-DM7ABOR. This increase of $G^{\prime}$ was more pronounced for the HA360-DM7ABOR hydrogel, which showed more than a 10fold enhancement in the storage modulus compared to the HA100-DM7ABOR system. The fact that only a 1.5-fold increase is observed for HA360-DMF6ABOR indicates that part of boronate ester bonds are not effective in interchain crosslink formation. This suggests a more significant increase of intrachain crosslinks with the increase of $H A M_{w}$, in comparison to HA-DM7ABOR. As $\mathrm{HA}$ is a semi-rigid polymer, ${ }^{41}$ it can be assumed that formation of intrachain crosslinks increases when increasing the HA molar mass.
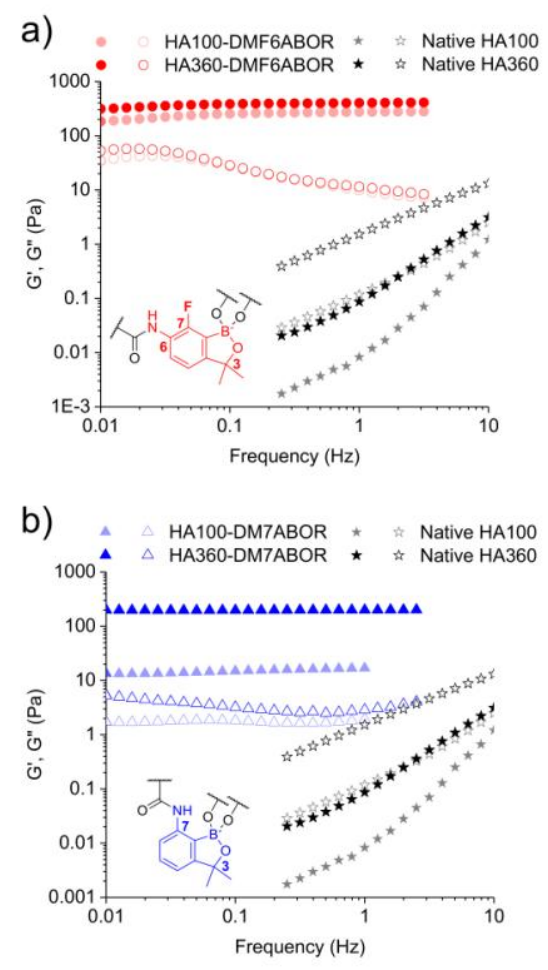

Figure 4. Frequency dependence of $G^{\prime}$ (filled symbols) and G" (empty symbols) for the formulations based on HA-DMF6ABOR (a) and HA-DM7ABOR (b) conjugates prepared from HA100 and HA360.

Interestingly, comparison of the ${ }^{1} \mathrm{H}$ NMR spectra of the HA360DMF6ABOR and HA360-DM7ABOR conjugates and of their HA100-DMF6ABOR and HA100-DM7ABOR counterparts showed an increase of the intensity of the proton signals assigned to the bound DMF6ABOR and DM7ABOR species (Figure S4, S6, S10 and $\mathrm{S} 11, \mathrm{SI})$. This increase appeared to be more pronounced for the HA-DM7ABOR derivatives.

Next, we investigated the dependence of gel strength on $\mathrm{pH}$ and on addition of competitive sugars. Rheological analysis of formulations based on HA360-DMF6ABOR (DM7ABOR) conjugates at $\mathrm{pH}$ ranging from 4.0 to 7.4 revealed network disassembly at $\mathrm{pH}$ around 6.5 in both cases (Figure 5). This is the likely consequence of the decrease of the DMF6ABOR (DM7ABOR)/HA saccharide affinity at lower $\mathrm{pH}$ values, taking into account that the affinity between boronic acids and diolcontaining molecules is $\mathrm{pH}$-dependent as previously mentioned.

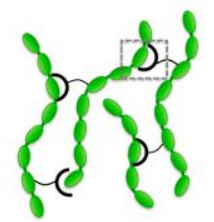

HA hydrogel

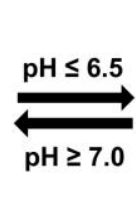

a)

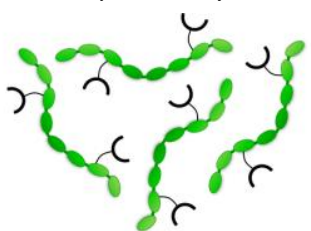

Gel disassembly

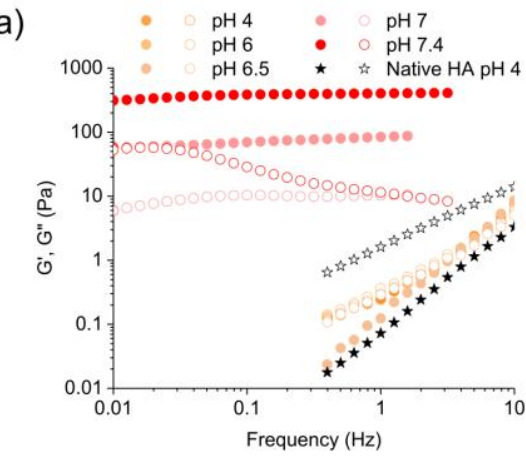

b)

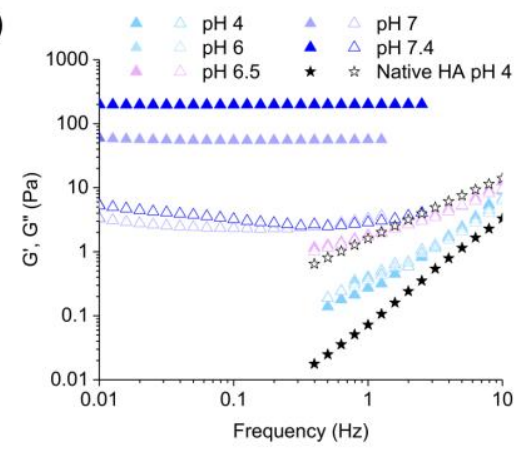

Figure 5. Frequency dependence of $\mathrm{G}^{\prime}$ (filled symbols) and $\mathrm{G}^{\prime \prime}$ (empty symbols) for the HA360-DMF6ABOR (a) and HA360DM7ABOR (b) formulations at $\mathrm{pH}$ values ranging from 4.0 to 7.4.

To gain insight into the binding affinity of DMF6ABOR and DM7ABOR for the HA saccharide units at physiological $\mathrm{pH}$, we performed competition experiments using fructose for which benzoxaborole has high affinity. ${ }^{22}$ Prior to these experiments, we determined the binding constants $\left(K_{a}\right)$ of the free $6 A B O R / D$ fructose, free DMF6ABOR/D-fructose, and free DM7ABOR/Dfructose complexes using isothermal titration calorimetry (ITC) 
and/or ${ }^{1} \mathrm{H}$ NMR spectroscopy for a better understanding of the results (Figure S14-S19, SI).

As the bound and unbound forms of 6ABOR (DM7ABOR) in the presence of fructose are clearly distinguishable by ${ }^{1} \mathrm{H} N M R$ spectroscopy at physiological pH (Figure S14 and S18, SI), allowing calculation of their proportion by integration of selected peaks and thereby, estimation of $K_{a}$, we also used this technique to evaluate directly the affinity of 6ABOR and DM7ABOR for Dfructose. As shown in Table 2, the $K_{a}$ values derived from NMR were found to be in relatively good agreement with those measured by ITC. Table 2 also shows higher binding affinity of DMF6ABOR for D-fructose in comparison to 6ABOR and DM7ABOR, displaying similar binding constants.

Table 2. Binding constants $\left(K_{a}\right)$ of free DMF6ABOR, DM7ABOR or 6ABOR with D-fructose at physiological $\mathrm{pH}$.

\begin{tabular}{ccccccc}
\hline Entry & Derivative & $\begin{array}{c}K_{a}^{\mathrm{a})} \\
\left(\mathrm{M}^{-1}\right)\end{array}$ & $\begin{array}{c}K_{a}^{\mathrm{b})} \mathrm{ITC} \\
\left(\mathrm{M}^{-1}\right)\end{array}$ & $\begin{array}{c}n^{\mathrm{b}}(n \\
\text { saccharide }: \\
1 \text { boronic } \\
\text { acid })\end{array}$ & $\begin{array}{c}\Delta H^{\mathrm{b})} \\
\left(\mathrm{KJ} \mathrm{mol}^{-1}\right)\end{array}$ & $\begin{array}{c}\left.\Delta \mathrm{S}^{\mathrm{b}}\right) \\
\left(\mathrm{J} \mathrm{mol}^{-}\right. \\
\left.1 \mathrm{~K}^{-1}\right)\end{array}$ \\
\hline 1 & 6ABOR & $461 \pm 73$ & $484 \pm 50$ & $1.24 \pm 0.1$ & $-11.7 \pm 2$ & 12.1 \\
2 & DMF6ABOR & $-\mathrm{c})$ & $1004 \pm 58$ & $0.85 \pm 0.05$ & $-19.1 \pm$ & 1.2 \\
3 & DM7ABOR & $778 \pm 41$ & $513 \pm 64$ & $1.2 \pm 0.15$ & $-19 \pm 2.8$ & -11.95 \\
\hline
\end{tabular}

${ }^{\text {a) }}$ Measured from at least two ${ }^{1} \mathrm{H}$ NMR experiments; ${ }^{b}$ measured from at least two ITC experiments; ${ }^{c)}$ not measured because ${ }^{1} \mathrm{H}$ signals of bound and unbound forms of DMF6ABOR were not sufficiently separated to be properly integrated.

Oscillatory shear measurements of HA360-DMF6ABOR and HA360-DM7ABOR after addition of 1 molar equivalent of Dfructose with respect to the grafted DMF6ABOR (DM7ABOR) moieties showed different behaviors (Figure $6 a$ and b). Indeed, complete network disassembly is obtained for HA360-DM7ABOR, while a 3-fold decrease of $G^{\prime}$ in the plateau region is observed for HA360-DMF6ABOR. The fact that the addition of only 1 molar equivalent of $D$-fructose is enough to compete with most of the benzoxaborole-HA crosslinks in the two networks demonstrates that the interaction of the BOR derivatives with $\mathrm{HA}$ is relatively weak. From this experiment, which indicates a lower sensitivity of the HA360-DMF6ABOR network to competitive D-fructose despite the higher $K_{a}$ value of DMF6ABOR/fructose than DM7ABOR/fructose, it can be inferred that DMF6ABOR has higher affinity for HA saccharide units than DM7ABOR. However, attempts to quantify the DMF6ABOR/HA affinity through the determination of $K_{a}$ using NMR spectroscopy failed. Although hydrogel formation from HA-DMF6ABOR conjugates provide macroscopic evidences of the formation of crosslinks between HA and grafted DMF6ABOR moieties, only the unbound form of DMF6ABOR could be observed in the ${ }^{1} \mathrm{H}$ NMR spectra in the presence of native HA, precluding $K_{a}$ measurement (Figure S20, $\mathrm{SI})$. This result makes us believe that the formation of complexes with HA only occurs in the polysaccharide-modified system, because this HA derivative presents multiple copies of DMF6ABOR receptors and of saccharide ligands, which promotes multivalent complexation.

Besides fructose, we also investigated the sensitivity of HA360DMF6ABOR (DM7ABOR) to D-glucose (Figure 6a and b). As seen from Figure $6 \mathrm{~b}$, almost complete gel disassembly was observed upon addition of 1 or 3 molar equivalent(s) of D-glucose (with respect to the grafted DM7ABOR moieties) to the HA-DM7ABOR network. This result is in agreement with the apparently weaker interaction of DM7ABOR moieties with HA, as previously indicated by the competition study using D-fructose. On the other hand, a gel-like behavior was still observed for HADMF6ABOR in the presence of glucose ( 1 or 3 equiv. of glucose/DMF6ABOR moiety, Figure 6a). Surprisingly, a slight increase of the plateau modulus is noticed for the HADMF6ABOR self-assembly in the presence of D-glucose (Figure 6a). Visual observations of this polymer network upon addition of D-glucose revealed formation of small gel fragments that remained bound together, indicating partial disruption of the macroscopic assembly due to the competitive interaction of DMF6ABOR moieties with glucose. The disruption of only a fraction of crosslinked HA chains thus changes the structure of the gel network and thereby, the bulk mechanical properties.
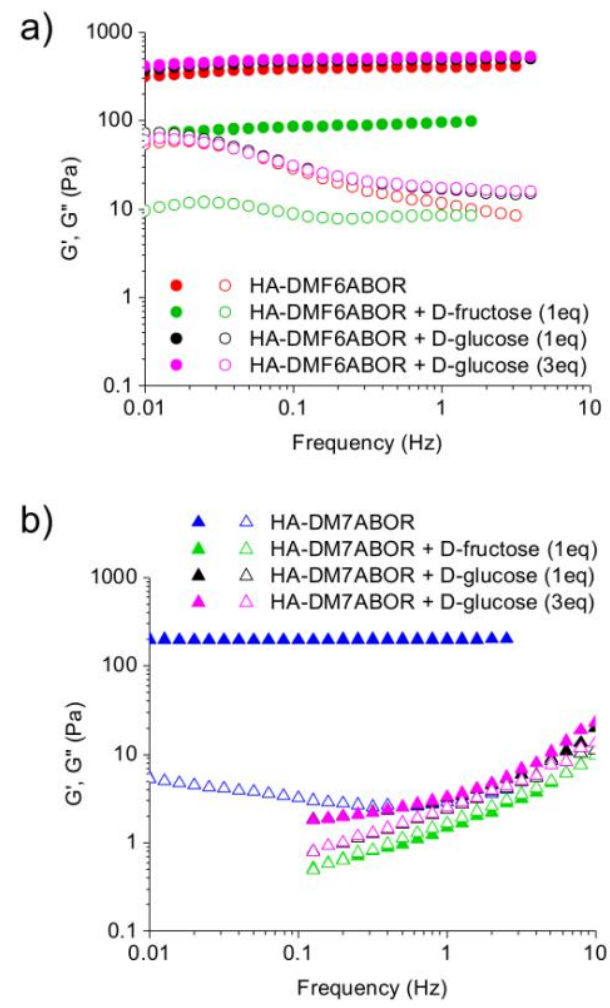

Figure 6. Dynamic rheological behavior of HA360-DMF6ABOR (a) and HA360-DM7ABOR (b) networks in the presence of free Dfructose (1 molar equivalent) or D-glucose ( 1 or 3 molar equivalent(s) with respect to the grafted BOR derivative).

Considering the different strengths of interaction of grafted DMF6ABOR (DM7ABOR) moieties with $H A$, we investigated the resistance of the HA360-DMF6ABOR (DM7ABOR) hydrogels to large strains, as well as their recovery by oscillatory shear experiments. Strain-dependent oscillatory rheology of the HA360-DMF6ABOR (DM7ABOR) networks displayed a broad linear viscoelastic region with network failure at high strains (approximately $400 \%$ for HA360-DMF6ABOR and $600 \%$ for HA360-DM7ABOR, Figure 7a and 7b). The networks were then found to self-heal immediately after removal of the applied strain, showing a recovery of most of their rheological properties 
(Figure 7a and 7b). Step-strain measurements were then performed to test the recovery of the benzoxaborole-HA properties following network rupture at high strains (a critical parameter for injectability). A high magnitude strain (300\% for the two hydrogels, corresponding to a drop of approximately 50 $\%$ in $\mathrm{G}^{\prime}$ ) was applied to break the hydrogel structure, followed by a low magnitude strain (5\%) to monitor the rate and extent of recovery 


\section{ARTICLE}

a)

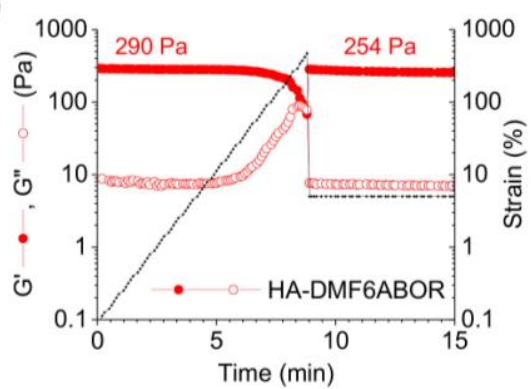

b)

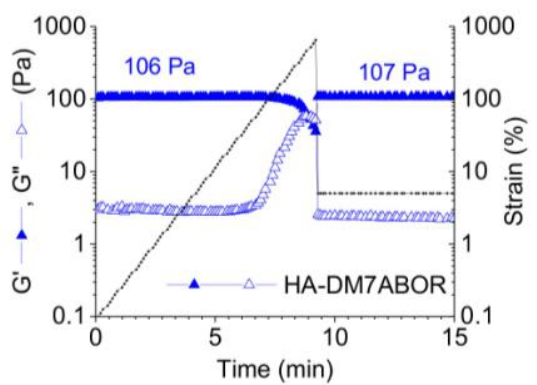

c)

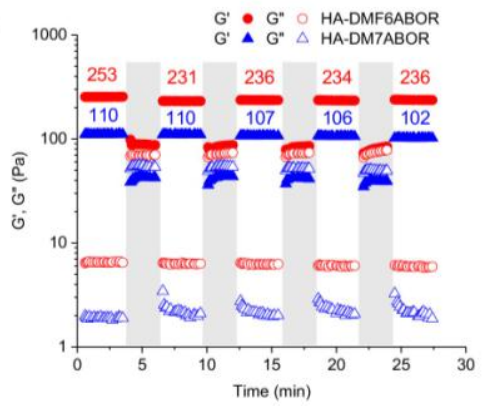

Figure 7. Self-healing of hydrogels after application of large strains. Variation of G' and G" for HA360-DMF6BOR (a) and HA360-DM7ABOR (b) when increasing strain, followed by the recovery of their moduli when strain is reduced. The gels fractured at a strain of, approximately, $400 \%$ (a) and $600 \%$ (b), and immediately recovered their moduli when strain was reduced to $5 \%$. (c) Four cycles of recovery from straininduced breakdowns at physiological pH: a strain above the linear viscoelastic region (shaded regions, $300 \%$ of strain) was applied for 2 $\min$, followed by linear recovery measurements during 3 min (unshaded regions, $5 \%$ of strain). of bulk properties (Figure 7c). After a series of four cycles of the role of the $\mathrm{p} K_{a}$ of boronic acid, it is generally believed that it is breaking and reforming, both hydrogels were able to retain a large percentage of their initial $G^{\prime}$ values within a 3 min recovery period (Figure 7c). However, it is important to note that the two HA networks behave differently. The HA360-DMF6ABOR gel was able to recover $\sim 80 \%$ of its initial elastic modulus, which was found to be independent of the $\mathrm{HA}$ molar mass, as a similar trend was observed for the HA100-DMF6ABOR hydrogel (Figure S21, SI). On the other hand, the HA360-DM7ABOR hydrogel showed a recovery of $\sim 90 \%$ of its initial $G^{\prime}$, indicating a better ability of this system to self-heal. The apparently higher interaction of DMF6ABOR with HA saccharides, leading to more strongly crosslinked HA chains, may provide some explanations for the divergent self-healing properties of the systems. It can be assumed that some chains have dramatically reduced mobility and remain resilient over a large range of strain, ${ }^{42}$ preventing complete gel disruption. As a result, the mechanical properties are not fully recovered because of a lower number of elastically active crosslinks in comparison to the initial hydrogel network. On the other hand, the apparently weaker interaction of DM7ABOR moieties with HA may lead to complete breaking of crosslinks and gel disintegration at large strains. This would allow nearly complete hydrogel restructuration, and a better recovery of the rheological properties.

All together, these results raise questions about the role of the structure of DMF6ABOR and DM7ABOR in the mechanism of HA crosslinking as well as in the different behavior of the HADMF6ABOR and HA-DM7ABOR hydrogels in response to chemical and mechanical stimuli.

\section{Discussion}

The outstanding capability of DMF6ABOR and DM7ABOR to crosslink HA chains may be explained by several factors. Regarding an important factor affecting carbohydrate recognition although there are exceptions in this trend. ${ }^{13}$ To assess the role of Lewis acidity, we measured the $\mathrm{p} K_{a}$ of DMF6ABOR and DM7ABOR by ${ }^{11} \mathrm{~B}$ NMR titration, resulting in $\mathrm{p} K_{a}$ values of 6.3 and 7.7 , respectively (Figure $\mathrm{S} 12, \mathrm{SI})$. Compared to standard benzoxaborole $\left(\mathrm{p} K_{a} 7.3^{40}\right)$ as well as 6-aminobenzoxaborole ( $\mathrm{p} K_{a} 6.7$, Figure S12, SI), DMF6ABOR is more acidic because of an expected electron-withdrawing effect of fluorine, whereas DM7ABOR has a higher $\mathrm{p} K_{a}$. These results indicate that other factors related to the structure of DMF6ABOR and DM7ABOR are of central importance in HA diol complexation. Regarding HA diols involved in the complexation, the structure of the polysaccharide, consisting of a repeating disaccharide unit of $D$ glucuronic acid (D-Glc) and $\mathrm{N}$-acetyl-D-glucosamine (D-GlcNAc, Figure 1), provides limited options for possible diol binding sites. Indeed, it has been reported

that for glucopyranosides, the only significant binding site for benzoxaborole is the $\mathrm{C}-4 / \mathrm{C}-6$ diol as all vicinal diols in this system are of a trans relationship. ${ }^{22}$ Therefore, it can be assumed that the C-4/C-6 diol of the D-GICNAC unit is the most probable site of complexation for the BOR derivatives, compared to the $\mathrm{C}-2 / \mathrm{C}-3$ diol pair of the D-Glc unit. Analysis of the DMF6ABOR (DM7ABOR) binding modes to $\mathrm{HA}$ by force field simulations confirmed this hypothesis. Molecular dynamics (MD) studies were made using a DMF6ABOR model containing a tert-butyl group coupled to its amide moiety to simulate the steric effect of the HA chain (Figure S22 and S13, SI). Simulations were performed on a HA with 2 repeating disaccharide units to confirm the involvement of the $C$ 4/C-6 diol of the D-GICNAC unit in the binding of the BOR moieties. Comparison between the binding models of DMF6ABOR to the $C$ 4/C-6 diol of D-GlcNAc and, alternatively, to the C-2/C-3 diol pair of D-Glc showed that, the first model provides a more favorable conformation of the benzoxaborole-HA complex as the ring 
conformation of D-GICNAc remains in a normal chair conformation thanks to the flexibility of the HA hydroxymethyl group (C-6, Figure S13a, SI). By contrast, the second model involves an unfavorable conformation of $\mathrm{HA}$, as this requires a large deformation of the $\mathrm{D}$ Glc ring unit of HA to form a complex with DMF6ABOR (Figure S13b, SI).

Having a look at the structures of the two BOR derivatives, they have, as a common feature, a gem-dimethyl group in the oxaborole ring which plays a key role in the binding to HA. As previously discussed, this group results macroscopically in a decrease of the network dynamics and in an increase of the dynamic moduli for most of the HA-DMABOR derivatives tested. The steric bulk caused by the Me substituents in the oxaborole ring likely alleviates the bond distortion around boron and releases ring strain (Figure S22, $\mathrm{SI})$. This effect, called gem-dimethyl effect, ${ }^{40}$ contributes to stabilize the geometry of the spiro adducts formed between BOR derivatives and $\mathrm{HA}$ diols. ${ }^{43,44}$ Moreover, the substituents in the ortho-position to boron center of both DMF6ABOR and DM7ABOR may provide additional stabilization of the benzoxaborole-HA complexes. To better understand the effect of these substituents, we investigated the molecular geometry of the complexes formed between HA diols and grafted DMF6ABOR (DM7ABOR) using MD studies. Based on the fact that the intrinsic persistence length of $\mathrm{HA}$, approximately 8 $\mathrm{nm},{ }^{45-48}$ is longer than the average separation between two BOR motifs in our system ( 6-10 $\mathrm{nm}$ deduced from the DS), one can consider that HA chains are rigid between two cross-linking points. Thus, the local geometry of cross-linking points is a decisive factor for the supramolecular assembly structures of HA chains. Simulations were performed with systems composed of two HA chains, each made of 6 repeating disaccharide units, possessing a single BOR-modified crosslinker covalently bound to both HA chains (approximately at the middle of each chain) (Figure 8). For comparison, besides two models including DMF6ABOR and DM7ABOR, we performed MD simulation with DM6ABOR as a crosslinker given that a macromolecular network with only viscoelastic properties was obtained when this derivative is grafted on HA (Figure 3a).

Very interestingly, the three systems studied formed distinct molecular organizations in our MD simulations (Figure 8). For more details, the angles between end-to-end vectors of two HA chains over the simulation time are shown in Figure S23a, which represents the mutual orientation of HA chains in each molecule. First, the two HA chains crosslinked by DM6ABOR adopted a parallel-aligned double chain conformation (Figure 8a), which was persistent over the whole simulation time (approximately $50 \mathrm{~ns}$ ). This organization is stabilized by interchain hydrogen bonds together with hydrophobic interactions between saccharide rings of HA due to the close proximity of the two chains. Moreover, in this conformation the DM6ABOR crosslinking point protruded from the double chain structure, which means that it did not virtually affect the interchain interactions. On the other hand, the two other systems based on HA chains crosslinked by DMF6ABOR or DM7ABOR moieties did not show this typical parallel-aligned double chain organization. The two HA chains are rather organized in crossed orientations (Figure $8 \mathrm{~b}$ and $8 \mathrm{c}$ ). In the case of DM7ABOR, the mutual rotation of the HA chains was blocked in the crossed orientation due to the proximity of the HA chains induced by the amide bond between one HA chain and DM7ABOR in the ortho position of the oxaborole ring. An almost similar conformation was observed for the model including DMF6ABOR as a crosslinker, despite this molecule possessed the same conformational flexibility than DM6ABOR at the crosslinking point. Therefore, it can be inferred that the particular crossed orientation observed for DMF6ABOR is due to the fluorine atom in the ortho position of the oxaborole ring. Indeed, the HA chains in this system are attracted towards the fluorine due to its hydrophobicity that contributes to expel water molecules from its neighborhood,

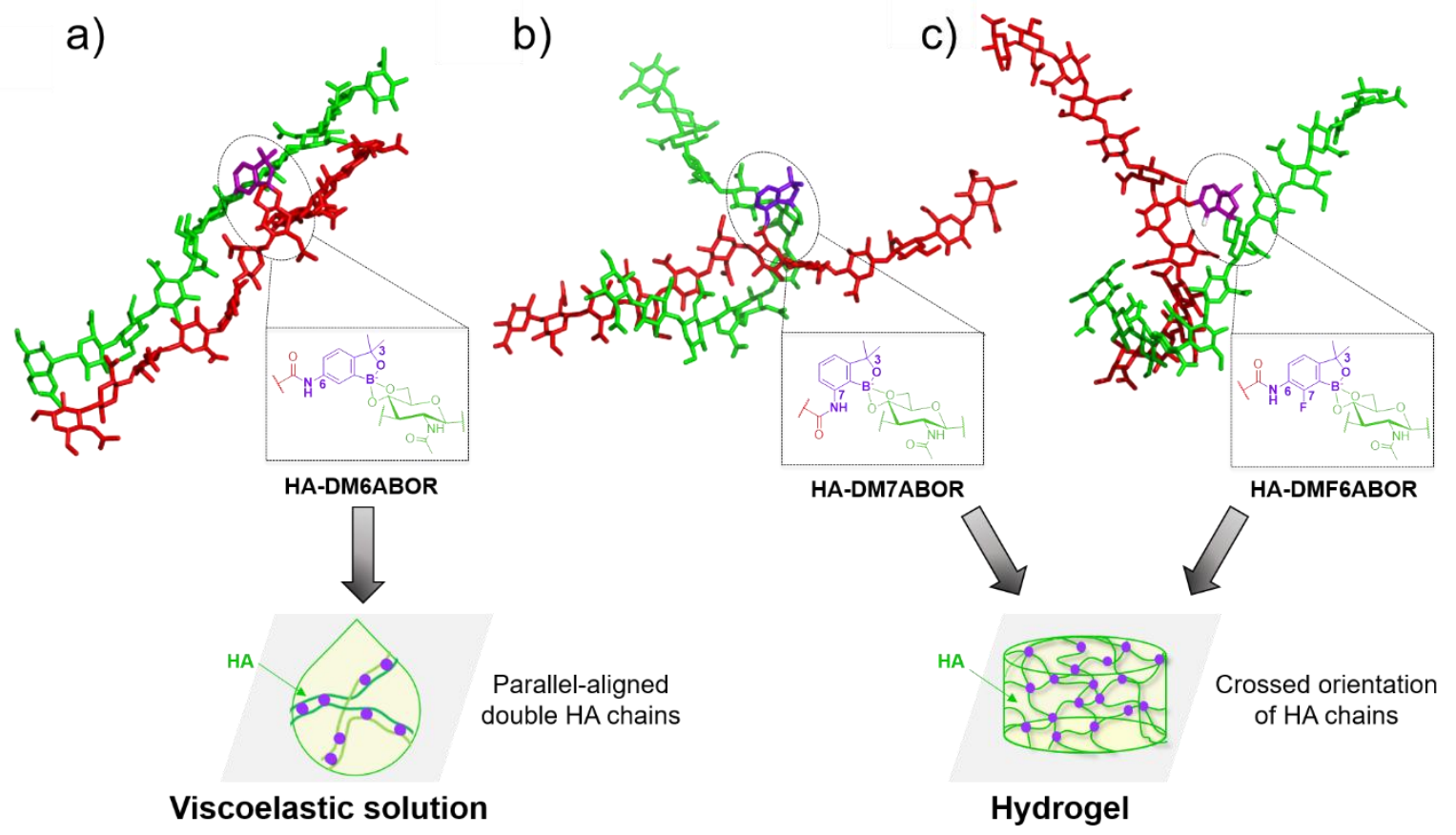

Figure 8. MD-simulated molecular organizations of HA chains cross-linked with DM6ABOR (a), DM7ABOR (b) and DMF6ABOR (c). The HA chains are organized in parallel-aligned double chains stabilized by several boronate ester bonds (represented as violet circles) in the 
system with DM6ABOR; an effective junction is formed when the double chains exchange their partners. For better representation, the HA chains are shown in light and darker green. In the other two systems, the HA chains are organized in crossed orientations.

resulting in an asymmetric $V$-shaped molecular organization of the two HA chains. Although HA chain organizations in these two systems are similar, the molecular mechanisms explaining their conformations are different. In the case of DM7ABOR, the crossed organization is controlled by the geometry of the dynamic covalent crosslinks formed between grafted DM7ABOR and HA, whereas the crossed organization in the DMF6ABOR system is mainly ascribed to the presence of a hydrophobic pocket. This gives greater flexibility around the crosslinking point, which results in a larger radius of gyration (Rg) compared to DM7ABOR (Figure S23b, SI). Thus, it can be assumed that the bulkier nature of the crosslinks between DMF6ABOR and HA may contribute to a higher volume occupancy at each crosslinking point and, therefore, to a more threedimensionally entangled HA network. Collectively, these results make us believe that these differences in the macromolecular architectures of the HA-DMF6ABOR and HA-DM7ABOR networks are the main reason for their divergent behaviors in response to chemical and mechanical stimuli (Figure 6 and 7).

Assuming that the macromolecular organization of HA-DMF6ABOR (HA-DM7ABOR) extends over the whole network, we believe that it acts in synergy with the formation of multiple crosslinks between $\mathrm{HA}$ sugars and DMF6ABOR (DM7ABOR) to induce formation of slowly relaxing hydrogel networks. The crossed orientation allows formation of entangled crossed HA chains with multiple BOR-HA crosslinks (Figure $3 a$ and $3 b$ ), which is likely the main contributing factor to the formation of networks with extremely slow dynamics perhaps by increasing the lifetime of junction points. Indeed, several studies performed on reversibly crosslinked networks demonstrated that the lifetime of the associative group in junction points is the primary determinant of the dynamic rheological properties of the network. ${ }^{49-53}$

By contrast, in the HA-DM6ABOR system, the parallel-aligned double chain conformation might induce formation of extended parallel double chain domains stabilized by several boronate ester bonds. Although these double chains can exchange their partners between them to form an effective junction, this macromolecular organization reduces the number of elastically effective chains (Figure 8a, bottom). This has already been reported for HA assemblies formed by host-guest interactions ${ }^{54}$ and may provide some explanation for the viscoelastic behavior observed in the present case. Based on these results, we believe that the outstanding rheological behavior of HA-DMFGABOR and HA$D M 7 A B O R$ is due to the formation of a highly entangled network of crossed HA chains caused by their crosslinking with the original BOR derivatives.

\section{Conclusions}

In summary, we report a new class of self-crosslinking smart hyaluronic acid hydrogels based on the multivalent complexation between custom-made benzoxaborole derivatives and the C-4/C- 6 diol of the HA D-GIcNAc unit. These novel $\mathrm{pH}$ - and carbohydrateresponsive hydrogels were prepared from a single component, hyaluronic acid modified with DMF6ABOR or DM7ABOR. The HA-
DMF6ABOR and HA-DM7ABOR conjugates are the first example of polysaccharide derivatives showing self-crosslinking properties via boronate ester bond formation at physiological $\mathrm{pH}$. The molecular origin of gelation behavior of these two HA derivatives lies in the unique structures of the grafted DMF6ABOR and DM7ABOR moieties. Indeed, the gem-dimethyl group in their heterocycle and the ortho-substituent in their phenyl ring play a key role in their efficient capability to crosslink HA. The presence of multiple copies of DMF6ABOR (DM7ABOR) receptors and of diol ligands in the HA derivatives is also an important factor contributing to the gelation mechanism. All these factors thus act in synergy to induce formation of highly entangled networks of crossed HA chains. These original architectures give the networks the particular features of having slow relaxation dynamics while being responsive to chemical and mechanical stimuli. These characteristics, combined with the unique biological properties of $\mathrm{HA}$, a polysaccharide which is ubiquitous in the body, make these new HA-based hydrogels promising candidates as injectable scaffolds for tissue engineering and cell therapy. Continued investigation of hyaluronic acid as well as other biocompatible polysaccharides modified with such benzoxaborole derivatives will open doors to address the challenge of injectable hydrogels and expand the application space for these materials such as in glucose-sensing and insulin-delivery as well as benzoxaborole-based lectin mimics to prevent viral infections.

\section{Conflicts of interest}

There are no conflicts to declare.

\section{Acknowledgements}

This work was supported by Galderma-Nestlé Skin Health. The authors thank Dr. C. Bouix-Peter at Galderma R\&D for valua-ble discussions; Santai Labs, Bellen Chemistry and GVK Bio-sciences for the custom synthesis of aminobenzoxaborole derivatives; the NMR platform of ICMG (FR2607) for its support as well as the CECIC Cluster (ICMG) used to perform MD simulations.

\section{Notes and references}

1 S. D. Bull, M. G. Davidson, J. M. H. van den Elsen, J. S. Fossey, A. T. A. Jenkins, Y.-B. Jiang, Y. Kubo, F. Marken, K. Sakurai, J. Zhao and T. D. James, Accounts of Chemical Research, 2013, 46, 312326.

2 J. N. Cambre and B. S. Sumerlin, Polymer, 2011, 52, 4631-4643.

3 V. Yesilyurt, M. J. Webber, E. A. Appel, C. Godwin, R. Langer and D. G. Anderson, Advanced Materials, 2016, 28, 86-91.

4 Y. Chen, W. Wang, D. Wu, M. Nagao, D. G. Hall, T. Thundat and R. Narain, Biomacromolecules, 2018, 19, 596-605.

5 Y. Chen, D. Diaz-Dussan, D. Wu, W. Wang, Y.-Y. Peng, A. B. Asha, D. G. Hall, K. Ishihara and R. Narain, ACS Macro Letters, 2018, 7, 904-908.

6 Y. Wang, L. Li, Y. Kotsuchibashi, S. Vshyvenko, Y. Liu, D. Hall, H. Zeng and R. Narain, ACS Biomaterials Science \& Engineering, 2016, 2, 2315-2323. 
7 B. Marco-Dufort and M. W. Tibbitt, Materials Today Chemistry, 2019, 12, 16-33.

8 Z. Wei, J. H. Yang, J. Zhou, F. Xu, M. Zrínyi, P. H. Dussault, Y. Osada and Y. M. Chen, Chem. Soc. Rev., 2014, 43, 8114-8131.

9 Y. Wang, C. K. Adokoh and R. Narain, Expert Opinion on Drug Delivery, 2018, 15, 77-91.

10 D. L. Taylor and M. in het Panhuis, Advanced Materials, 2016, 28, 9060-9093.

11 D. G. Hall, Boronic Acis: Preparation and Applications in Organic Synthesis, Medicine and Materials, Wiley- $\mathrm{VCH}$, Weinheim, Germany, Second edition., 2011, vol. 2.

12 W. L. A. Brooks and B. S. Sumerlin, Chemical Reviews, 2016, 116 1375-1397.

13 J. Yan, G. Springsteen, S. Deeter and B. Wang, Tetrahedron, 2004, 60, 11205-11209.

14 G. Springsteen and B. Wang, Tetrahedron, 2002, 58, 5291-5300.

15 D. Li, Y. Chen and Z. Liu, Chemical Society Reviews, 2015, 44, 8097-8123.

16 H. R. Mulla, N. J. Agard and A. Basu, Bioorganic \& Medicinal Chemistry Letters, 2004, 14, 25-27.

17 C. Zhang, M. D. Losego and P. V. Braun, Chemistry of Materials, 2013, 25, 3239-3250.

18 A. Adamczyk-Woźniak, M. K. Cabaj, P. M. Dominiak, P. Gajowiec, B. Gierczyk, J. Lipok, Ł. Popenda, G. Schroeder, E. Tomecka, P. Urbański, D. Wieczorek and A. Sporzyński, Bioorganic Chemistry, 2015, 60, 130-135.

19 X. Yang, M.-C. Lee, F. Sartain, X. Pan and C. R. Lowe, Chemistry A European Journal, 2006, 12, 8491-8497.

20 C. C. Deng, W. L. A. Brooks, K. A. Abboud and B. S. Sumerlin, ACS Macro Letters, 2015, 4, 220-224.

21 M. Dowlut and D. G. Hall, Journal of the American Chemical Society, 2006, 128, 4226-4227.

22 M. Bérubé, M. Dowlut and D. G. Hall, The Journal of Organic Chemistry, 2008, 73, 6471-6479.

23 J. A. Peters, Coordination Chemistry Reviews, 2014, 268, 1-22.

24 A. Adamczyk-Woźniak, K. M. Borys and A. Sporzyński, Chemical Reviews, 2015, 115, 5224-5247.

25 C. T. Liu, J. W. Tomsho and S. J. Benkovic, Bioorganic \& Medicinal Chemistry, 2014, 22, 4462-4473.

26 Y. Kotsuchibashi, R. V. C. Agustin, J.-Y. Lu, D. G. Hall and R. Narain, ACS Macro Letters, 2013, 2, 260-264.

27 M. Lin, P. Sun, G. Chen and M. Jiang, Chem. Commun., 2014, 50 , 9779-9782.

28 Y. Kotsuchibashi, M. Ebara, T. Sato, Y. Wang, R. Rajender, D. G. Hall, R. Narain and T. Aoyagi, The Journal of Physical Chemistry $B, 2015,119,2323-2329$.

29 T. Figueiredo, J. Jing, I. Jeacomine, J. Olsson, T. Gerfaud, J.-G. Boiteau, C. Rome, C. Harris and R. Auzély-Velty, Biomacromolecules, 2020, 21, 230-239.

30 A. Pettignano, S. Grijalvo, M. Häring, R. Eritja, N. Tanchoux, F. Quignard and D. Díaz Díaz, Chemical Communications, 2017, 53 3350-3353.

31 C. W. G. Macosko, Rheology: Principles, Measurements, and Applications, VCH Publishers, Weinheim, Germany, 1994.

32 I. M. Krieger, Journal of Rheology, 1990, 34, 471-483.

33 R. E. Hudson, A. J. Holder, K. M. Hawkins, P. R. Williams and D. J. Curtis, Physics of Fluids, 2017, 29, 121602.

34 M. J. Abraham, T. Murtola, R. Schulz, S. Páll, J. C. Smith, B. Hess and E. Lindahl, SoftwareX, 2015, 1-2, 19-25.

35 N. Schmid, A. P. Eichenberger, A. Choutko, S. Riniker, M. Winger, A. E. Mark and W. F. van Gunsteren, Eur Biophys J, 2011, 40, 843.
36 G. Bussi, D. Donadio and M. Parrinello, The Journal of Chemical Physics, 2007, 126, 014101.

37 H. J. C. Berendsen, J. P. M. Postma, W. F. van Gunsteren, A. DiNola and J. R. Haak, The Journal of Chemical Physics, 1984, 81, 3684-3690.

38 H. J. C. Berendsen, J. P. M. Postma, W. F. van Gunsteren and J. Hermans, in Intermolecular Forces, Springer, Dordrecht, 1981, pp. 331-342.

39 M. D'Este, D. Eglin and M. Alini, Carbohydrate Polymers, 2014, 108, 239-246.

40 J. W. Tomsho, A. Pal, D. G. Hall and S. J. Benkovic, ACS Medicinal Chemistry Letters, 2012, 3, 48-52.

41 E. R. Morris, D. A. Rees and E. J. Welsh, Journal of Molecular Biology, 1980, 138, 383-400.

$42 \mathrm{~K}$. Yu, A. Xin and Q. Wang, Journal of the Mechanics and Physics of Solids, 2018, 121, 409-431.

43 M. E. Jung and G. Piizzi, Chemical Reviews, 2005, 105, 17351766.

44 J. L. Frahn, Journal of Chromatography A, 1984, 314, 167-181.

45 S. Ghosh, X. Li, C. E. Reed and W. F. Reed, Biopolymers, 1990, 30, 1101-1112.

46 E. Fouissac, M. Milas, M. Rinaudo and R. Borsali, Macromolecules, 1992, 25, 5613-5617.

47 K. Haxaire, I. Braccini, M. Milas, M. Rinaudo and S. Pérez, Glycobiology, 2000, 10, 587-594.

48 E. Buhler and F. Boué, Macromolecules, 2004, 37, 1600-1610.

49 E. A. Appel, J. del Barrio, X. J. Loh and O. A. Scherman, Chem. Soc. Rev., 2012, 41, 6195-6214.

50 W. C. Yount, D. M. Loveless and S. L. Craig, Journal of the American Chemical Society, 2005, 127, 14488-14496.

51 O. R. Cromwell, J. Chung and Z. Guan, Journal of the American Chemical Society, 2015, 137, 6492-6495.

52 W. C. Yount, D. M. Loveless and S. L. Craig, Angewandte Chemie International Edition, 2005, 44, 2746-2748.

53 W. Shen, J. A. Kornfield and D. A. Tirrell, Macromolecules, 2007, 40, 689-692.

54 A. Semenov, A. Charlot, R. Auzély-Velty and M. Rinaudo, Rheologica Acta, 2007, 46, 541-568. 